\title{
A Unified Concept of Acne in the PAPA Spectrum Disorders
}

\author{
Flavie Maitrepierre ${ }^{a}$ Angelo Valerio Marzano ${ }^{b}$ Dan Lipsker ${ }^{a, c}$ \\ ${ }^{a}$ Dermatology Clinic, Strasbourg University and Strasbourg University Hospitals, Strasbourg, France; ${ }^{b}$ Dipartimento \\ di Fisiopatologia Medico-Chirurgica e dei Trapianti, Università degli Studi di Milano, Unità Operativa di

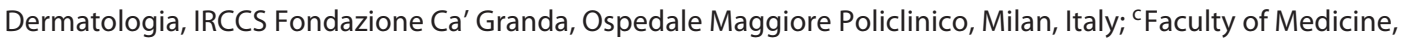 \\ University of Strasbourg, Strasbourg, France
}

\section{Keywords}

Acne $\cdot$ PAPA syndrome $\cdot$ PSTPIP1 gene $\cdot$ Interleukin-1

inhibitors · Isotretinoin

\section{Abstract}

Background: Acne is a common condition. Sometimes acne or acne-like features are a part of autoinflammatory diseases such as PAPA spectrum disorders. Our objective was to determine whether acne in PAPA spectrum disorders has specific phenotypic traits. Summary: This is a literature review on reported cases of patients with PAPA, PAMI, PASH, PAPASH, PsAPASH, PAC or PASS syndrome. Acne was classified into four categories: moderate, severe, nodulocystic, acne fulminans. One hundred patients were included. Age of onset of acne and topography were the same as in acne vulgaris. Acne's phenotype was at least severe (including acne fulminans, nodulocystic and severe) in $83 \%$ of cases. Genetic mutations or variants with potential pathological significance were reported in 49 patients. The addition of isotretinoin to biotherapies was required to control acne in several patients.

(c) 2020 S. Karger AG, Basel

\section{Introduction}

Acne may be one of the most common pathologies dermatologists are called upon to treat, but it is nevertheless complex, belonging to various aetiological frameworks, including autoinflammatory diseases.

The term "autoinflammatory disease" designates a series of pathologies caused by tissue damage arising from an excessive activation of the innate immune system. Diverse clinical features may suggest autoinflammatory disease: recurrent febrile outbreaks, various skin lesions, serositis, arthralgia, bowel disorders or ophthalmological manifestations. One of the cutaneous manifestations described is acne. The term acne even forms part of the acronyms of certain entities, for which it is also a diagnostic criterion. PAPA syndrome was described for the first time in 1997 by Lindor et al. [1] as the triad of pyogenic sterile arthritis, pyoderma gangrenosum (PG) and acne. However, acne is not essential to diagnosis, which can be ascertained with certainty in 2 situations according to Lindor's definition: family members who are 16 years of age or older are karger@karger.com

www.karger.com/drm

(c) 2020 S. Karger AG, Base

Karger ${ }^{\prime}=$
Flavie Maitrepierre

Dermatology Clini

Strasbourg University and Strasbourg University Hospitals

1, place de l'Hôpital, FR-67091 Strasbourg Cedex (France)

flavie.maitrepierre@gmail.com 
Table 1. Main characteristics of patients with PAPA spectrum disorders

\begin{tabular}{|c|c|c|c|c|c|c|c|c|}
\hline Syndrome, $n$ & $\begin{array}{l}\text { Ratio } \\
\mathrm{M} / \mathrm{F}\end{array}$ & $\begin{array}{l}\text { Average age } \\
\text { at diagnosis, years }\end{array}$ & $\begin{array}{l}\text { Average age at } \\
\text { onset of acne, years }\end{array}$ & $\begin{array}{l}\text { Nodulocystic } \\
\text { acne, } n\end{array}$ & $\begin{array}{l}\text { Acne } \\
\text { fulminans, } n\end{array}$ & $\begin{array}{l}\text { Severe } \\
\text { acne, } n\end{array}$ & $\begin{array}{l}\text { Moderate } \\
\text { acne, } n\end{array}$ & Genetic data: $n$ \\
\hline $\begin{array}{l}\text { PAPA [49] } \\
\text { with acne [37], } \\
\text { including } 4 \text { PAMI }\end{array}$ & 2.4 & 37 & 13 & 17 & 1 & 5 & 9 & PSTPIP1 gene mutation: 30 \\
\hline $\begin{array}{l}\text { PAPA without acne [12], } \\
\text { including } 1 \text { PAMI }\end{array}$ & 5 & 22 & - & - & - & - & - & PSTPIP1 gene mutation: 6 \\
\hline PASH [43] & 2.1 & 33 & 17 & 13 & 5 & 12 & 1 & $\begin{array}{l}\text { PSTPIP } 1 \text { gene mutation: } 2 \\
\text { Increased repeats (CCTG): } 6 \\
\text { Potentially pathogenic gene } \\
\text { variants: } 8\end{array}$ \\
\hline PASS [2] & $2 / 0$ & 33 & 13 & 2 & - & - & - & - \\
\hline PAPASH [4] & 1 & 31 & 15 & 2 & - & - & 2 & PSTPIP1 gene mutation: 1 \\
\hline PsAPASH [1] & $1 / 0$ & 50 & - & - & - & - & - & - \\
\hline PAC [1] & $1 / 0$ & 33 & - & 1 & - & - & - & PSTPIP1 gene mutation: 1 \\
\hline
\end{tabular}

classified as definitely affected if they had 2 of 3 major findings: sterile pyogenic arthritis, pyoderma gangrenosum or severe acne. Adults with 1 major finding are considered probably affected. Family members younger than 16 years of age are considered affected if sterile pyogenic arthritis is substantiated in 2 or more joints. Other syndromes similar to PAPA were later identified and can be unified under the umbrella designation PAPA spectrum disorders: PASH syndrome (PG, acne and hidradenitis suppurativa (HS)), PASS (PG, acne, seronegative spondyloarthritis, with or without HS), PAPASH (features of PASH with pyogenic arthritis), PsAPASH (PASH with psoriatic arthritis) and PAC (PG, acne and ulcerative colitis). PAMI syndrome (PSTPIP1-associated myeloid-related proteinaemia inflammatory syndrome) is a variant of PAPA syndrome for which the haematological manifestations are characteristic [2].

Autoinflammatory diseases are often treated and described by paediatricians, rheumatologists and internists for whom dermatological symptomatology is unfamiliar. Two legitimate questions thus arise: (1) whether the lesions described as "acne" occurring in the course of autoinflammatory diseases correspond truly to the definition of this pathology, and (2) whether any clinical elements confer specific features to the acne observed in this context. The goal of this study is therefore to provide a precise phenotypic analysis of lesions described as acne during PAPA spectrum syndromes.

\section{Materials and Methods}

In the PubMed database, using the advanced search options, a query on the terms "PAPA" (or "PAMI"), "PASH," "PAPASH," "PSAPASH," "PASS" and "PAC" was conducted on all the article titles available. All the article titles thus obtained were examined. The remaining articles were then read.

Then we conducted a second series of searches, one for each syndrome: the term "acne" defined as the MeSH (Medical Subject Headings) major topic was combined successively with each of the following terms: PAPA, PASH, PASS, PAPASH, PsAPASH and PAC, without any limit on date.

The selection of articles was then repeated as in first series of searches, and the articles not having been identified were included.

Likewise, a third series of searches was conducted for each syndrome, using key words looking at the combination of separate components within the syndromes, without filtering. Articles not having been identified with the two previous series of searches were added.

All cases with acne were thus categorised by phenotype of the acne, according to the following definitions:

- moderate acne: corresponds to the merger of the first two grades of the Global Alliance Classification: comedonal acne and mild-moderate papulopustular acne;

- severe acne: severe papulopustular acne or moderate nodular acne according to the Global Alliance Classification:

- severe nodular acne or conglobate acne according to the Global Alliance Classification;

- acne fulminans: inflammatory suppurative nodules progressing to necrotic ulcers, with pronounced general signs (high fever, myalgia, arthralgia).

When no precise phenotypic analyses or images were available to enable determination of the acne phenotype, we relied on the terms used by the authors. 
Table 2. Treatments considered effective during PAPA spectrum disorders: acne outcomes and phenotypes

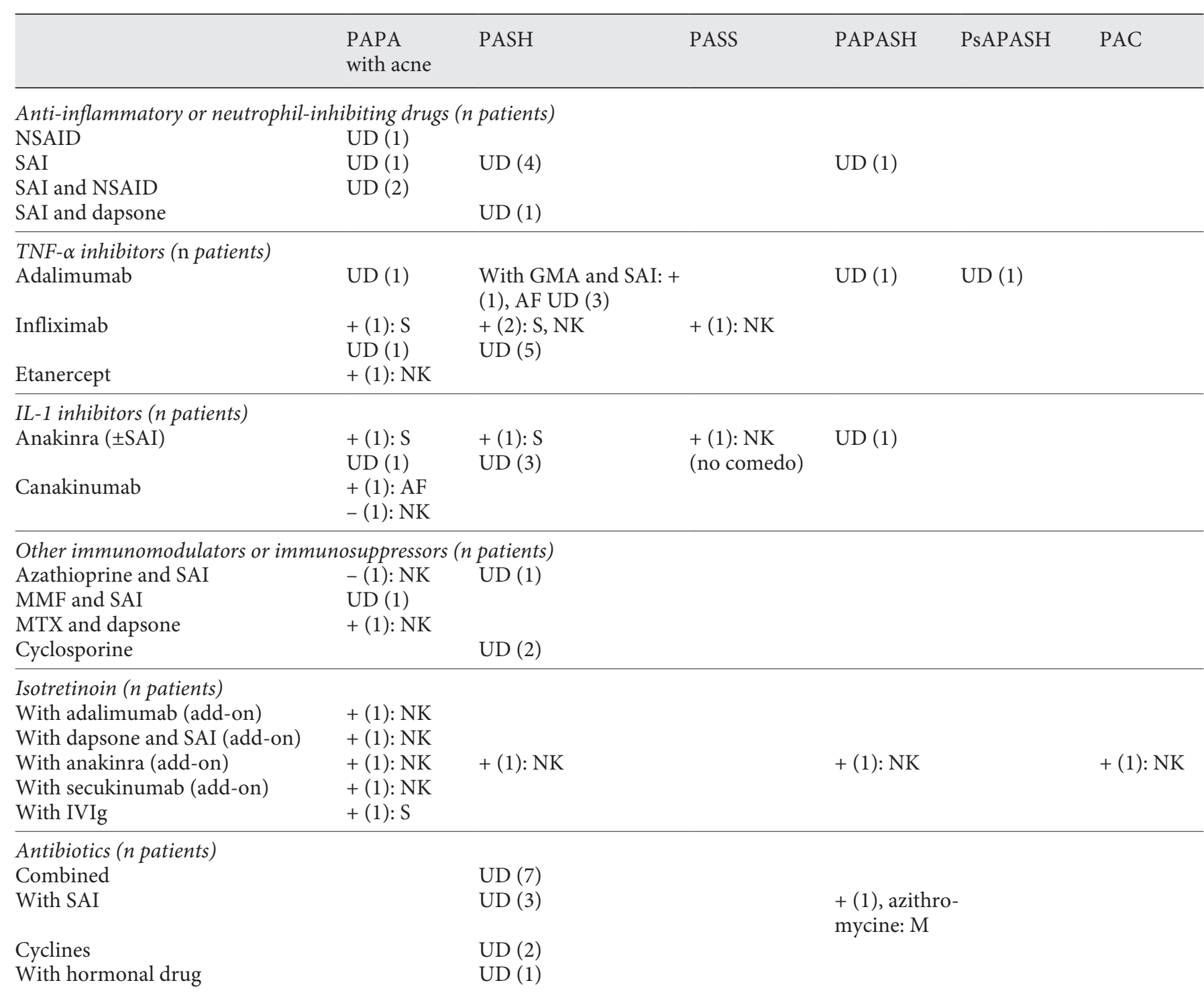

+, positive acne outcome; -, negative acne outcome; UD, undetermined acne outcome; GMA, granulocyte and monocyte adsorption apheresis; IVIg, intravenous immunoglobulin; MMF, mycophenolate mofetil; MTX, methotrexate; NSAID, non-steroidal anti-inflammatory drug; SAI, steroidal anti-inflammatory drug. Phenotype of the acne: M, moderate; S, severe; NK, nodulocystic; AF, acne fulminans.

\section{Results}

There were 49 cases of PAPA syndrome, of which 12 without acne and 5 belonging to the PAMI subgroup, 43 cases of PASH, 4 cases of PAPASH, 2 cases of PASS, 1 case of PsAPASH and 1 case of PAC. Key patient data are summarised in Table 1 . The sex ratio $(\mathrm{M} / \mathrm{F})$ was 2.2. The average age at syndromic diagnosis was 33 years. In PAPA syndrome, the first syndromic element to appear was pyogenic arthritis, at an average age of 8 years (known for $70 \%$ of cases). The order of appearance was variable for the other syndromes, starting at puberty. The average age of onset of acne was 15 years. The acne phenotype was established in $80 \%$ of cases. Acne was at least severe (nodulocystic, acne fulminans or severe but without the characteristics of the 2 previous phenotypes) in $83 \%$ of cases. 
The topography of the lesions was that of acne vulgaris (face, trunk), with 4 cases involving the scalp. Data concerning treatments are summarised in Table 2.

\section{PAPA Syndrome}

Forty-nine cases were identified in all the articles included, of which 37 with acne (76\%). It should be noted that 5 cases of PAPA were observed in children under 10 who did not (yet?) have acne; they were not included in the analysis, because acne in PAPA syndrome occurs from puberty onwards. Five cases made up a PAMI subgroup, including 1 patient without acne. Male patients made up most of both groups (sex ratio M/F 2.4 in the group with acne, and 5 in the group without). The average age at syndromic diagnosis was 37 years (range: $11-$ 63 ) in the group with acne and 22 (range: 13-49) in the group without. The first symptom of the diagnostic triad to appear was almost systematically arthritis in both groups, with joint symptoms first occurring at an average age of 8 years (range: $1-33$ ) in the group with acne and 5 years (range: 3 months to 8 years) in the group without.

The average age of acne onset was 13 years (range: 10 18). For 8 patients, acne was still present at the age of diagnosis (in their 20s or 30s, and even at age 63 in 1 case [1]). When the location was specified (35\% of cases), acne was on the face $(n=6,46 \%)$, the face and trunk $(n=6$, $46 \%)$ and the trunk alone $(n=1,8 \%)$. The acne phenotype was established in $87 \%$ of patients: 17 (53\%) had nodulocystic acne, including 1 with an analytic description, not mentioning comedones and accompanied by 2 images confirming the phenotype [3]. One case (3\%) was defined as acne fulminans, with images and a clinical history consistent with this finding: outbreaks of fever with nodular, more or less necrotic lesions [4]. Nine cases (28\%) corresponded to moderate acne. Five cases (16\%) were categorised as severe acne.

No biopsies of acne lesions were performed, but 4 PG biopsies and 2 of the synovium showed infiltration rich in polynucleated neutrophils.

In $80 \%$ of patients of both groups, the results of genetic analyses were available. In 36 cases (92\%), a mutation of the PSTPIP1 (CD2BP1) gene was discovered, with only 1 case that was homozygous [4], in the group with acne. There was no mutation of the PSTPIP1 gene in 3 patients $(8 \%)$ in the group with acne $[3,5,6]$. The mutations were similar in both groups.

We observed the following associations: 3 cases of type 2 diabetes in male patients [1] and 1 case of gestational diabetes [1], 1 case of psoriasis in a male patient [7], pso- riatic arthritis in the mother of 1 patient [8], rheumatoid arthritis in the brother of a patient having the same PSTPIP1 gene mutation [9], uveitis in 1 male patient [7], bouts of abdominal pain with fever, HS and antiphospholipid syndrome in 1 female patient [10], 4 cases of inflammatory colitis [8,11-13], 1 case of acute myeloid leukaemia [14].

\section{PASH Syndrome}

Forty-three cases were found in the literature, including 9 cases [15-18] reported before the description of the syndrome in 2012 under the name "PASH" [19]. The sex ratio $(\mathrm{M} / \mathrm{F})$ was 2.1. The average age at diagnosis was 33 years (11-48). All cases had acne. The average age of acne onset was 17 years (11-33). The progression of acne over time was rarely described (data for 5 cases). In 4 cases acne persisted until the age of diagnosis. Acne was most often the first syndromic element to appear (62\% of cases), at adolescence, sometimes concurrently with HS $(23 \%)$. Acne occurred on the face in $57 \%$ of cases, the face and trunk in $33 \%$ of cases, and in 2 cases $(10 \%)$ on the scalp and face.

The acne phenotype was established in $72 \%$ of cases. Thirteen cases (42\%) corresponded to nodulocystic acne, of which 3 with photographs supporting this conclusion [20-22], and 4 descriptive analyses. Five cases (16\%), all in male patients, were categorised as acne fulminans, including 2 accompanied by images consistent with this conclusion [23, 24]. In 12 cases (39\%), acne was described as severe; 2 of these cases had a descriptive analysis specifying the predominance of inflammatory lesions over retentional lesions [20]. Three photos supported this phenotype, including 1 where comedones were observed [25]. One male patient had moderate acne. A photo illustrated the case, and comedones were described as predominating over inflammatory lesions [20]. We noted 20 cases for which a cutaneous biopsy indicated PG, and 1 pustule biopsy from the lower back with results indicating polynucleated neutrophil folliculitis, and where no comedones were described.

Results of genetic analyses varied for the $75 \%$ of patients for whom such analyses were mentioned: 3 cases (9\%) had a mutation of the PSTPIP1 gene [26-28], 6 (19\%) had an increase in the number of CCTG microsatellites in the PSTPIP1 promoter region, $8(25 \%)$ had at least 1 gene mutation or variant implicated in other inflammatory diseases, and 12 (34\%) had no anomalies in the genes analysed.

We observed the following associations: 8 patients of the 9 for whom the body mass index was known were 
overweight/obese, 1 had a bariatric surgery [29], and 1 patient had type 2 diabetes [30]. Joint inflammation occurred in 5 patients $[17,20,23,31]$, and there was 1 case of osteopoikilosis [32]. Three patients had inflammatory colitis [15, 20,33], 1 female patient had a polycystic ovary syndrome [22], and another had hirsutism [34]

\section{PASS Syndrome}

The 2 articles included concerned 2 male patients aged 32 and 33 years; the authors established their acne phenotype as nodulocystic, with involvement of the face and trunk. For 1 of them, a descriptive analysis was provided, and a photo illustrated the acne's nodulocystic character [35]. The age of onset of acne was 13 years for 1 patient and was unknown for the other. No particular mutation was found.

\section{PAPASH Syndrome}

Four cases were found, with an average diagnostic age of 31 years (16-44). The average age at the onset of acne was 15 years. There were 2 female patients, whose acne was graded as moderate. One of the articles included a photo confirming this phenotype [36]. The acne phenotype in the 2 male cases was nodulocystic, and a photo of 1 of these patients showed severe acne scarring on the face [37]. A biopsy confirmed the diagnosis of PG for all these patients. A mutation of the PSTPIP1 gene was reported for 1 female patient [38]. No mutation was found for 2 other cases, and no data were available for the remaining case. An inflammatory colitis was associated in 1 male patient [37].

\section{PsAPASH Syndrome}

The sole article included [39] reported a 50-year-old male patient with a clearly dysmetabolic profile; the phenotype of his acne was not clearly specified. The authors reported inflammatory lesions (pustules) and retentional lesions (open comedones). The genetic aspect was not covered.

\section{PAC Syndrome}

The only case of PAC reported [40] was in a male patient, 33 years old, with nodulocystic acne. A descriptive analysis supported this phenotype, mentioning comedones, and photos illustrated it. An outbreak of pustulosis occurred 2 years after the beginning of the inflammatory colitis. Genetic analysis revealed a mutation of the PSTPIP1 gene, of unknown significance. Its deleterious effect is probable, however, as it concerned a highly conserved region of the gene.

PAPA Spectrum Disorders

\section{Discussion}

This review of the literature confirms that acne is frequent in subjects with PAPA spectrum syndromes, that it occurs at the usual age for acne, and that it is generally severe: these elements suggest that the genetic predisposition to inflammation induced by these entities could simply modulate the expression of this common dermatosis and that it is not strictly speaking a manifestation of the disease.

In most cases, the authors categorise acne by phenotype, without indications of a careful morphological analysis to support their conclusion. Only 12 cases benefited from a descriptive analysis of the active elementary lesions of acne. Among these descriptions, 6 mentioned the presence of comedones: 4 in the course of PASH syndrome [25, 29, 41, 42], 1 in the course of PsAPASH [39] and 1 in the course of PAC [40]. One article reported the presence of retentional lesions in 2 patients suffering from PASH syndrome with severe acne [20]. Careful morphological analysis of acne in the course of these diseases is therefore patchy, but where acne's characteristic elementary lesion, the comedo, is mentioned it is highly probable that these patients' skin lesions were in fact acne. Moreover, the related images spoke for themselves.

Phenotyping appeared homogenous for the 6 syndromes studied: it was at least severe for $83 \%$ of patients for whom the phenotype could be determined. In unselected patients, only $8-28 \%$ of cases of acne vulgaris are considered severe, however, bearing in mind that few precise data exist concerning the epidemiology of acne phenotype $[43,44]$. The much more pronounced severity of these cases is possibly attributable to excess inflammation during these diseases.

Indeed, the overexpression of proinflammatory cytokines, especially in PAPA $[9,11]$, PASS [45] and PASH syndromes [25], has been observed in the skin or in the blood. In Marzano et al. [25], proinflammatory cytokine overexpression such as IL-1b, IL-17, TNF- $\alpha$ and their receptors were significant in PASH syndrome, but also in PG outside any syndromic framework. The mutations identified in isolated cases of PASH and PG were different, but concerned the same genes implicated in diverse autoinflammatory diseases (MEFV, NLRP3, NLRP12, NOD2, LPIN2 and PSTPIP1). This suggests a continuum comprising all these different entities, which all belong to the same spectrum.

The main genetic mutations reported in PAPA syndrome are of autosomal dominant inheritance. Nesterovitch et al. [46] described the case of a male patient with 
PG associated with a minor form of acne and inflammatory arthralgia, for whom a heterozygous PSTPIP1 mutation was observed, suggesting a minor form of PAPA syndrome. The same mutation in the homozygous state was found in a patient with PAPA syndrome, with major skin lesions, including acne fulminans [4]. The expression and penetrance of a gene can also vary between individuals. Indeed, family forms with autosomal dominant inheritance in which different phenotypes occur within a single family have been described $[4,9,11,25,28,47]$.

Severe acne could itself include an autoinflammatory component. Several diseases for which polynucleated neutrophils are central to their pathogenesis, including spondyloarthropathy, chronic bowel inflammation diseases and atrophic polychondritis, share common manifestations (neutrophilic dermatosis, acne, chondritis, axial inflammatory rheumatism). Those symptoms are also observed during PAPA spectrum disorders.

Thus, just as an association of neutrophilic dermatosis with seronegative polyarthritis or inflammatory colitis has been observed, these diseases have been described in association with PAPA spectrum syndromes. In this review of the literature, 8 patients (8\%) had an inflammatory colitis. The association of PG with acne and inflammatory colitis has been established as an entity unto itself (PAC) [40]. One case [29] developed PASH syndrome 2 years after bariatric surgery, highlighting this overlap. We can make a link with the bowel-associated dermatitis arthritis syndrome, known to be a complication of jejunoileal bypass during which cutaneous symptoms belonging to the spectrum of neutrophilic dermatoses have been reported [48-50].

PASS, PAPASH and PsAPASH syndromes include inflammatory joint manifestations, sometimes with psoriasis. Several patients had inflammatory joint symptoms that do not belong to the syndromic criteria of those diseases. Therefore, if rheumatological and digestive symptoms occur even if they do not belong to the components of a given syndrome, any distinction between those diseases seems to be artificial. We find it more appropriate to group them under the term "PAPA spectrum disorders."

Genetic origin is well established in the PAPA syndrome. The mutation of the PSTPIP1 gene results in an augmentation of the binding capacity of CD2BP1 with pyrin, which induces an increase first in caspase 1 , then in the production of IL-1. PSTPIP1 mutations have also been described in the course of PAPASH and PAC. For $\mathrm{PASH}$ syndrome, where the genetic data are more heterogeneous, we can postulate a polygenic origin involving the same inflammation pathways. Genetic investigation was sometimes limited to the analysis of the PSTPIP1 gene, which may explain why no anomalies were reported. It is not clear whether patients affected by other autoinflammatory syndromes with increased IL-1 synthesis, such as cryopyrinopathies or deficiency of interleukin 1 receptor antagonist, also develop severe acne.

The dysmetabolic background associated with these pathologies is also interesting to note, in particular with PASH syndrome $[22,29,51]$. It is very probably underestimated: among the PASH cases with reported body mass index, only 1 was normal. This comorbidity is the same as for psoriasis, HS and PG. Hsiao et al. [16] reported that 13 patients in a series of 31 suffering from PG and HS had acne, and the association with obesity was consistent. Two other case-control studies confirmed the epidemiological correlation between obesity and HS $[52,53]$. The link between overweight and acne vulgaris has often been described in the literature, placing it within a social and cultural context $[54,55]$. This appears to be linked to the hyperactivation of the signalling pathway for mammalian target of rapamycin complex 1, caused by food consumption become too rich in fast sugars in developed countries, associated with an unfavourable metabolic deviation and heightened insulin resistance [56]. In the course of autoinflammatory syndromes, overweight can be both a consequence and a cause of inflammatory dysfunction: a consequence of a genetic predisposition, and a cause of chronic inflammation and of hyperandrogenism.

In the specific context of inflammasome dysfunction, treatments administered go beyond conventional therapeutic measures for acne, sometimes directly targeting excess inflammatory cytokines. In most cases, systemic treatments are adopted to treat manifestations other than acne, such as pyogenic arthritis, polyarthritis, PG or inflammatory colitis, because of their greater impact on quality of life. In this manner, inhibitors targeting TNF- $\alpha$ (mainly adalimumab, etanercept and infliximab) and IL-1 (anakinra, canakinumab) have been successful, with a favourable response specified also for acne in some cases $[4,9,23,29,57,58]$. As we can see in Table 2, some patients did not respond to first-line anti-inflammatory treatments and required association with isotretinoin as add-on: this holds for PAPA syndrome $[3,11,59,60]$, PASH [19], PAPASH [30] and PAC [40]. In these cases, all patients had a cystic acne. In contrast, we can point to a failure of response of a cystic acne to canakinumab, while a case of acne fulminans responded favourably to this treatment. One patient with a PASS syndrome and a nodulocystic acne had a good response to anakinra, but it should be noted that the authors described inflammatory lesions (nodules and pustules) without comedones [35]. 
Unfortunately, in the majority of published reports, acne outcome is not described, which limits our conclusions. Therefore, this observation illustrates once again the complex interaction of multiple factors in the pathogenesis of acne, including in the course of autoinflammatory syndromes, in which the inflammation is undeniably predominant but not exclusive, comprising other components which are not targeted by cytokine inhibitors.

\section{Conclusion}

In the course of PAPA spectrum syndromes, severe acne seems to be the result of overexpression of its inflammatory component, in the context of genetic predisposition to exaggerated inflammatory response. Autoinflammatory diseases therefore offer a new approach to understanding the physiopathology of acne.

\section{Key Message}

Acne in PAPA spectrum syndromes is characterised by an extreme inflammatory component, possibly owing to a genetic predisposition that modulates the expression of this common dermatosis. Therefore, it is not strictly speaking a manifestation of the disease, and management involves treatment targeting the inflammation, associated to conventional treatments for acne.

\section{Disclosure Statement}

The authors have no conflicts of interest to declare.

\section{Author Contributions}

Flavie Maitrepierre did data collections and wrote the article under the supervision of Dan Lipsker, instigator of this study, while Angelo Valerio Marzano contributed by proofreading, as an expert in this field.

\section{References}

1 Lindor NM, Arsenault TM, Solomon H, Seidman CE, McEvoy MT. A new autosomal dominant disorder of pyogenic sterile arthritis, pyoderma gangrenosum, and acne: PAPA syndrome. Mayo Clin Proc. 1997 Jul;72(7):611-5.

2 Holzinger D, Roth J. Alarming consequences - autoinflammatory disease spectrum due to mutations in proline-serine-threonine phosphatase-interacting protein 1. Curr Opin Rheumatol. 2016 Sep;28(5):550-9.

3 Hong JB, Su YN, Chiu HC. Pyogenic arthritis, pyoderma gangrenosum, and acne syndrome (PAPA syndrome): report of a sporadic case without an identifiable mutation in the CD2BP1 gene. J Am Acad Dermatol. 2009 Sep;61(3):533-5.

4 Geusau A, Mothes-Luksch N, Nahavandi H, Pickl WF, Wise CA, Pourpak Z, et al. Identification of a homozygous PSTPIP1 mutation in a patient with a PAPA-like syndrome responding to canakinumab treatment. JAMA Dermatol. 2013 Feb;149(2):209-15.

5 Horiuchi I, Fukatsu Y, Ushijima J, Nakamura E, Samajima K, Kadowaki K, et al. A pregnancy-associated nonfamilial case of PAPA (pyogenic sterile arthritis, pyoderma gangrenosum, acne) syndrome. Clin Case Rep. 2016 Sep;4(10):989-91.

6 Park BM, Yun SJ, Lee SC, Lee JB. A sporadic case of pyogenic arthritis, pyoderma gangrenosum and acne syndrome without an identifiable mutation. Clin Exp Dermatol. 2014 Jan;39(1):73-5.

7 Tallon B, Corkill M. Peculiarities of PAPA syndrome. Rheumatology (Oxford). 2006 Sep;45(9):1140-3.

8 Lindwall E, Singla S, Davis WE, Quinet RJ. Novel PSTPIP1 gene mutation in a patient with pyogenic arthritis, pyoderma gangreno- sum and acne (PAPA) syndrome. Semin Arthritis Rheum. 2015 Aug;45(1):91-3.

9 Cortis E, De Benedetti F, Insalaco A, Cioschi S, Muratori F, D'Urbano LE, et al. Abnormal production of tumor necrosis factor (TNF) alpha and clinical efficacy of the TNF inhibitor etanercept in a patient with PAPA syndrome [corrected] [corrected]. J Pediatr. 2004 Dec;145(6):851-5.

10 Schellevis MA, Stoffels M, Hoppenreijs EP, Bodar E, Simon A, van der Meer JW. Variable expression and treatment of PAPA syndrome. Ann Rheum Dis. 2011 Jun;70(6):1168-70.

11 Demidowich AP, Freeman AF, Kuhns DB, Aksentijevich I, Gallin JI, Turner ML, et al. Brief report: genotype, phenotype, and clinical course in five patients with PAPA syndrome (pyogenic sterile arthritis, pyoderma gangrenosum, and acne). Arthritis Rheum. 2012 Jun;64(6):2022-7.

12 Schäffler H, Blattmann T, Findeisen A, Meinel FG, Meyer-Bahlburg A, Lamprecht G, et al. [PAPA syndrome with Crohn's disease and primary sclerosing cholangitis/autoimmune hepatitis overlap syndrome]. Hautarzt. 2019 Feb;70(2):116-22.

13 Yeon HB, Lindor NM, Seidman JG, Seidman CE. Pyogenic arthritis, pyoderma gangrenosum, and acne syndrome maps to chromosome 15q. Am J Hum Genet. 2000 Apr;66(4):1443-8.

14 Lambertucci JR. Fever of undetermined origin in a patient with pyogenic arthritis, pyoderma gangrenosum, and acne (PAPA syndrome). Rev Soc Bras Med Trop. 2014 JanFeb;47(1):122.

15 Moschella SL. Is there a role for infliximab in the current therapy of hidradenitis suppurativa? A report of three treated cases. Int J Dermatol. 2007 Dec;46(12):1287-91.
16 Hsiao JL, Antaya RJ, Berger T, Maurer T, Shinkai K, Leslie KS. Hidradenitis suppurativa and concomitant pyoderma gangrenosum: a case series and literature review. Arch Dermatol. 2010 Nov; 146(11):1265-70.

17 Shenefelt PD. Pyoderma gangrenosum associated with cystic acne and hidradenitis suppurativa controlled by adding minocycline and sulfasalazine to the treatment regimen. Cutis. 1996 May;57(5):315-9.

18 Ah-Weng A, Langtry JA, Velangi S, Evans $\mathrm{CD}$, Douglas WS. Pyoderma gangrenosum associated with hidradenitis suppurativa. Clin Exp Dermatol. 2005 Nov;30(6):669-71.

19 Braun-Falco M, Kovnerystyy O, Lohse P, Ruzicka T. Pyoderma gangrenosum, acne, and suppurative hidradenitis ( $\mathrm{PASH}$ ) - a new autoinflammatory syndrome distinct from PAPA syndrome. J Am Acad Dermatol. 2012 Mar;66(3):409-15.

20 Marzano AV, Ceccherini I, Gattorno M, Fanoni D, Caroli F, Rusmini M, et al. Association of pyoderma gangrenosum, acne, and suppurative hidradenitis (PASH) shares genetic and cytokine profiles with other autoinflammatory diseases. Medicine (Baltimore). 2014 Dec;93(27):e187.

21 Sonbol H, Duchatelet S, Miskinyte S, Bonsang B, Hovnanian A, Misery L. PASH syndrome (pyoderma gangrenosum, acne and hidradenitis suppurativa): a disease with genetic heterogeneity. $\mathrm{Br}$ J Dermatol. 2018 Jan; 178(1):e17-8

22 Zivanovic D, Masirevic I, Ruzicka T, BraunFalco M, Nikolic M. Pyoderma gangrenosum, acne, suppurative hidradenitis (PASH) and polycystic ovary syndrome: coincidentally or aetiologically connected? Australas J Dermatol. 2017 May;58(2):e54-9. 
23 Mizutani Y, Okano T, Takahashi T, Ohnishi $\mathrm{H}$, Ohara O, Sano A, et al. Pyoderma gangrenosum, acne and suppurative hidradenitis syndrome treated with granulocyte and monocyte adsorption apheresis. Acta Derm Venereol. 2017;97(2):275-6.

24 Join-Lambert O, Duchatelet S, Delage M, Miskinyte S, Coignard H, Lemarchand N, et al. Remission of refractory pyoderma gangrenosum, severe acne, and hidradenitis suppurativa (PASH) syndrome using targeted antibiotic therapy in 4 patients. J Am Acad Dermatol. 2015 Nov;73(5 Suppl 1):S66-9.

25 Marzano AV, Damiani G, Ceccherini I, Berti E, Gattorno M, Cugno M. Autoinflammation in pyoderma gangrenosum and its syndromic form (pyoderma gangrenosum, acne and suppurative hidradenitis). Br J Dermatol. 2017 Jun;176(6):1588-98.

26 Saito N, Minami-Hori M, Nagahata H, Nozaki $\mathrm{H}$, Iinuma $\mathrm{S}$, Igawa $\mathrm{S}$, et al. Novel PSTPIP1 gene mutation in pyoderma gangrenosum, acne and suppurative hidradenitis syndrome. J Dermatol. 2018 Aug;45(8):e213-4.

27 Jennings L, Molloy O, Quinlan C, Kelly G, O'Kane M. Treatment of pyoderma gangrenosum, acne, suppurative hidradenitis (PASH) with weight-based anakinra dosing in a Hepatitis B carrier. Int J Dermatol. 2017 Jun;56(6):e128-9.

28 Calderón-Castrat X, Bancalari-Díaz D, RománCurto C, Romo-Melgar A, Amorós-Cerdán D, Alcaraz-Mas LA, et al. PSTPIP1 gene mutation in a pyoderma gangrenosum, acne and suppurative hidradenitis (PASH) syndrome. Br J Dermatol. 2016 Jul;175(1):194-8.

29 Marzano AV, Ishak RS, Colombo A, Caroli F, Crosti C. Pyoderma gangrenosum, acne and suppurative hidradenitis syndrome following bowel bypass surgery. Dermatology. 2012; 225(3):215-9.

30 Faleri S, Feichtner K, Ruzicka T. [Severe acne in autoinflammatory diseases]. Hautarzt. 2016 Nov;67(11):897-901.

31 McCarthy S, Foley CC, Dvorakova V, Quinlan C, Murphy M, Maher M. PASH syndrome with bony destruction. Clin Exp Dermatol. 2019 Dec;44(8):918-20.

32 Gracia-Cazaña T, Frias M, Roselló R, VeraÁlvarez J, Gilaberte Y. PASH syndrome associated with osteopoikilosis. Int J Dermatol. 2015 Sep;54(9):e369-71.

33 Murphy B, Morrison G, Podmore P. Successful use of adalimumab to treat pyoderma gangrenosum, acne and suppurative hidradenitis (PASH syndrome) following colectomy in ulcerative colitis. Int J Colorectal Dis. 2015 Aug; 30(8):1139-40.

34 Ead JK, Snyder RJ, Wise J, Cuffy C, Jafary H, Fischborn K. Is PASH Syndrome a Biofilm Disease?: A Case Series and Review of the Literature. Wounds. 2018 Aug;30(8):216-23.

35 Leuenberger M, Berner J, Di Lucca J, Fischer L, Kaparos N, Conrad C, et al. PASS Syndrome: An IL-1-Driven Autoinflammatory Disease. Dermatology. 2016;232(2):254-8.
36 Garzorz N, Papanagiotou V, Atenhan A, Andres C, Eyerich S, Eyerich K, et al. Pyoderma gangrenosum, acne, psoriasis, arthritis and suppurative hidradenitis (PAPASH)-syndrome: a new entity within the spectrum of autoinflammatory syndromes? J Eur Acad Dermatol Venereol. 2016 Jan;30(1):141-3.

37 Ursani MA, Appleyard J, Whiteru O. Pyogenic arthritis, pyoderma gangrenosum, acne, suppurative hidradenitis (PA-PASH) syndrome: an atypical presentation of a rare syndrome. Am J Case Rep. 2016 Aug;17:587-91.

38 Marzano AV, Trevisan V, Gattorno M, Ceccherini I, De Simone C, Crosti C. Pyogenic arthritis, pyoderma gangrenosum, acne, and hidradenitis suppurativa (PAPASH): a new autoinflammatory syndrome associated with a novel mutation of the PSTPIP1 gene. JAMA Dermatol. 2013 Jun;149(6):762-4.

39 Saraceno R, Babino G, Chiricozzi A, Zangrilli A, Chimenti S. PsAPASH: a new syndrome associated with hidradenitis suppurativa with response to tumor necrosis factor inhibition. J Am Acad Dermatol. 2015 Jan;72(1):e42-4.

40 Zeeli T, Padalon-Brauch G, Ellenbogen E, Gat A, Sarig O, Sprecher E. Pyoderma gangrenosum, acne and ulcerative colitis in a patient with a novel mutation in the PSTPIP1 gene. Clin Exp Dermatol. 2015 Jun;40(4):367-72.

41 De Wet J, Jordaan HF, Kannenberg SM, Tod B, Glanzmann B, Visser WI. Pyoderma gangrenosum, acne, and suppurative hidradenitis syndrome in end-stage renal disease successfully treated with adalimumab. Dermatol Online J. 2017 Dec;23(12):13030/qt82d4m2zw.

42 Koshelev MV, Garrison PA, Wright TS. Concurrent hidradenitis suppurativa, inflammatory acne, dissecting cellulitis of the scalp, and pyoderma gangrenosum in a 16-year-old boy. Pediatr Dermatol. 2014 Jan-Feb;31(1):e20-1.

43 Bloch B. Metabolism, endocrine glands and skin diseases, with special reference to acne vulgaris and xanthoma. Br J Dermatol. 1931; 43(2):77-87.

44 Daniel F, Dréno B, Dropsy R. Epidémiologie descriptive de l'acné dans la population scolarisée en France métropolitaine pendant l'automne 1996. Ann Dermatol Vénéréol. 2000 Apr;127(3):273.

45 Vinkel C, Thomsen SF. Autoinflammatory syndromes associated with hidradenitis suppurativa and/or acne. Int J Dermatol. 2017 Aug;56(8):811-8.

46 Nesterovitch AB, Hoffman MD, Simon M, Petukhov PA, Tharp MD, Glant TT. Mutations in the PSTPIP1 gene and aberrant splicing variants in patients with pyoderma gangrenosum. Clin Exp Dermatol. 2011 Dec; 36(8):889-95

47 Caorsi R, Picco P, Buoncompagni A, Martini A, Gattorno M. Osteolytic lesion in PAPA syndrome responding to anti-interleukin 1 treatment. J Rheumatol. 2014 Nov;41(11): $2333-4$.
48 Cantatore FP, Carrozzo M, Loperfido MC. Post biliopancreatic bypass arthritis. Dermatitis syndrome. Clin Rheumatol. 1991 Dec; 10(4):449-51.

49 Shagrin JW, Frame B, Duncan H. Polyarthritis in obese patients with intestinal bypass. Ann Intern Med. 1971 Sep;75(3):377-80.

50 Delaney TA, Clay CD, Randell PL. The bowelassociated dermatosis-arthritis syndrome. Australas J Dermatol. 1989;30(1):23-7.

51 Staub J, Pfannschmidt N, Strohal R, BraunFalco M, Lohse P, Goerdt S, et al. Successful treatment of PASH syndrome with infliximab, cyclosporine and dapsone. J Eur Acad Dermatol Venereol. 2015 Nov;29(11):22437.

52 Revuz JE, Canoui-Poitrine F, Wolkenstein P, Viallette C, Gabison G, Pouget F, et al. Prevalence and factors associated with hidradenitis suppurativa: results from two case-control studies. J Am Acad Dermatol. 2008 Oct;59(4): 596-601.

53 Crowley JJ, Mekkes JR, Zouboulis CC, Scheinfeld N, Kimball A, Sundaram M, et al. Association of hidradenitis suppurativa disease severity with increased risk for systemic comorbidities. Br J Dermatol. 2014 Dec;171(6): 1561-5.

54 Tsai MC, Chen W, Cheng YW, Wang CY, Chen GY, Hsu TJ. Higher body mass index is a significant risk factor for acne formation in schoolchildren. Eur J Dermatol. 2006 MayJun;16(3):251-3.

55 Halvorsen JA, Vleugels RA, Bjertness E, Lien L. A population-based study of acne and body mass index in adolescents. Arch Dermatol. 2012 Jan;148(1):131-2.

56 Melnik BC. Acne vulgaris: the metabolic syndrome of the pilosebaceous follicle. Clin Dermatol. 2018 Jan - Feb;36(1):29-40.

57 Brenner M, Ruzicka T, Plewig G, Thomas P, Herzer P. Targeted treatment of pyoderma gangrenosum in PAPA (pyogenic arthritis, pyoderma gangrenosum and acne) syndrome with the recombinant human interleukin-1 receptor antagonist anakinra. Br J Dermatol. 2009 Nov;161(5):1199-201.

58 Lee H, Park SH, Kim SK, Choe JY, Park JS Pyogenic arthritis, pyoderma gangrenosum, and acne syndrome (PAPA syndrome) with $\mathrm{E} 250 \mathrm{~K}$ mutation in $\mathrm{CD} 2 \mathrm{BP} 1$ gene treated with the tumor necrosis factor inhibitor adalimumab. Clin Exp Rheumatol. 2012 May-Jun; 30(3):452.

59 Klötgen HW, Beltraminelli H, Yawalkar N, van Gijn ME, Holzinger D, Borradori L. The expanding spectrum of clinical phenotypes associated with PSTPIP1 mutations: from PAPA to PAMI syndrome and beyond. Br J Dermatol. 2018 Apr;178(4):982-3.

60 Edrees AF, Kaplan DL, Abdou NI. Pyogenic arthritis, pyoderma gangrenosum, and acne syndrome (PAPA syndrome) associated with hypogammaglobulinemia and elevated serum tumor necrosis factor-alpha levels. J Clin Rheumatol. 2002 Oct;8(5):273-5. 